\title{
Hypertension in Clinical Practice: Control Rate in Short Term and Associated Factors in the Cardiology Department of the University Hospital Gabriel Touré (UH-GT) in Bamako (Mali)
}

\author{
Hamidou Oumar Bâ ${ }^{*}$, Ichaka Menta1, Ibrahima Sangare1, Youssouf Camara ${ }^{2}$, Noumou Sidibe1, \\ Souleymane Coulibaly3, Djénébou Traoré4, Réné Dakouo1, Samba Samaké1, Aladji Traoré1, \\ Samba Sidibé3, Mamadou Cissouma1, Cheick Hamala Fofana ${ }^{1}$, Lamine Sidibe', \\ Kassoum Mamourou Sanogo ${ }^{1}$
}

\author{
${ }^{1}$ University Hospital Gabriel Touré, Bamako, Mali \\ ${ }^{2}$ University Hospital Kati, Kati, Mali \\ ${ }^{3}$ University Hospital Point G, Bamako, Mali \\ ${ }^{4}$ University Hospital of Mali, Bamako, Mali \\ Email: ^bhamiba@yahoo.fr
}

How to cite this paper: Bâ, H.O., Menta, I., Sangare, I., Camara, Y., Sidibe, N., Coulibaly, S., Traoré, D., Dakouo, R., Samaké, S., Traoré, A., Sidibé, S., Cissouma, M., Fofana, C.H., Sidibe, L. and Sanogo, K.M. (2018) Hypertension in Clinical Practice: Control Rate in Short Term and Associated Factors in the Cardiology Department of the University Hospital Gabriel Touré (UHGT) in Bamako (Mali). World Journal of Cardiovascular Diseases, 8, 288-297. https://doi.org/10.4236/wjcd.2018.86028

Received: May 4, 2018

Accepted: June 10, 2018

Published: June 13, 2018

Copyright $\odot 2018$ by authors and Scientific Research Publishing Inc. This work is licensed under the Creative Commons Attribution International License (CC BY 4.0).

http://creativecommons.org/licenses/by/4.0/

\begin{abstract}
Introduction: Hypertension (HTN) is for many decades a worldwide major risk factor for cardiovascular disease. However, hypertension control rates are globally low in the world. Studies on observance have been published in Mali but there is to our knowledge no published data about HTN control rate. We therefore conducted this study to assess the control rate in short term after 3 months management and to look for factors associated with HTN control. Materials and Methods: This study designed as prospective was conducted in the cardiology department of the University Hospital Gabriel Touré (UH-GT) from March 24 to September 24, 2017. All outpatients aged 18 years and more who came for visit and with hypertension as diagnose were involved. All patients have consented to participate in the study. Sociodemographic and data on physical examination including measures for BP, height, weight, waist circumference (WC) and direct costs as reported by the patients were recorded. Patients were asked about medication discontinuation and if yes why and then they were informed about the need to take regularly medication. The concept of chronic disease was explained to them. A formulary served to collect data that were inserted into a Microsoft Access database and analyzed using SPSS version 18. After describing of sociodemographics and continuous variables,
\end{abstract}


crosstabs and finally a logistic regression was performed to look for blood pressure control predictors. Results: There was no statistical difference in sociodemographics between older and newly diagnosed patients. At 3 months globally $40.90 \%$ (31.1 for old Patients and $09.8 \%$ for new Patients) of the sample were controlled (Figure 1). For old patients, hypertension control rate at inclusion was $12.78 \%$ and reached $49.44 \%$ at 3 months (Figure 2). After logistic regression only HTN duration was significant predictor with Odd-ratio of 0.365 [0.213 - 0.624] 95\% CI and $p$-value $<0.001$ (old patients as reference). During the study period therapeutic regimen remained unchanged in $73.1 \%$ (44.4 for old Patients and 28.7 for new Patients. Calcium channel blocker (CCB), diuretics (DIU) and ACE-inhibitors (ACE-I) were the most prescribed drugs without statistical difference between patients with and without blood pressure under control. Conclusion: Short term hypertension control rate is low and patient follow-up must incorporate information at each visit as well as information through others channels for preventing hypertension. The duration of hypertension was found to be predictor for hypertension control.

\section{Keywords}

Hypertension, Control Rate, Old Patient, New Patient, Medication, Bamako, Outpatient

\section{Introduction}

Hypertension (HTN) has been recognized for many decades as worldwide major risk factor for cardiovascular disease. HTN is a major public health issue not only responsible for near 9.4 million deaths yearly but represent a high economic burden mainly for low- and middle-income countries [1]. Based on estimations, the number of hypertensive patients will rise from $26.4 \%$ in 2000 to $29.2 \%$ in 2025 representing 1.56 billion adults [2]. Moreover, it exists different patterns in cardiovascular mortality and also HTN, low- and middle-income countries being more affected [3].

These facts make it clear that HTN should be addressed through different components [1] among them integrated primary care program for control of HTN.

However, hypertension control rates are globally low in the world ranging from $34 \%$ to $66 \%$ in North-America [4] [5] [6]. There are also improvements in control rate as published by McAlister [7], Gupta [8] in urban Indian population but any improvement in awareness, treatment and control rates in India [9]. Even in particular group such HIV-patients, the control rate of HTN remains low [9]. Globally there is a marked difference in control rate between countries [10].

Many factors have such blood pressure (BP) prior HTN diagnostic, awareness of hypertension and lifestyle modification been identified as common for HTN control [11] or access to a regular source of health care and modification of lifestyle for He J et al. [12]. 
Studies on observance have been published in Mali but there is to our knowledge no published data about HTN control rate. We therefore conducted this study to assess the control rate in short term after 3 months management and to look for factors associated with HTN control.

\section{Methods}

This study designed as prospective was conducted in the cardiology department of the UH-GT from March 24 to September 24 2017. All outpatients aged 18 years and more who came for visit and with hypertension as diagnosis were involved. All patients have consented to participate in the study.

A formulary has been filled for each patient and data concerned sociodemographic and data on physical examination including measures for BP, height, weight, waist circumference (WC) and direct costs as reported by the patients. At each visit patients were first asked about medication discontinuation and if yes why and then they were informed about the need to take regularly medication. The concept of chronic disease was explained to them.

All anthropometrical measures were done following WHO recommendations. Calculated value was body mass index (BMI) as weight $(\mathrm{Kg}) /$ height $(\mathrm{m})$ squared.

High blood pressure (HBP) was retained for BP values of $\geq 140 \mathrm{mmHg}$ systolic and $\geq 90 \mathrm{mmHg}$ diastolic.

General obesity (Gob) was defined for BMI $\geq 30 \mathrm{Kg} / \mathrm{m}^{2}$ and abdominal Obesity (AOb) for $\mathrm{WC} \geq 102 \mathrm{~cm}$ for men and $\geq 88 \mathrm{~cm}$ for women. At each visit patients have been informed about hypertension and the need to continually take medicine.

Following classifications were used:

1) based on duration: old Patients for patients known as hypertensive patients before inclusion in the study and new Patients for patients knewly diagnosed as hypertensive patients.

2) based on hypertension control at 3 months: in $\operatorname{Ctrl}(+)$ for patients with blood pressure controlled and $\mathrm{Ctrl}(-)$ for those which blood pressure was not controlled.

Collected data were inserted in a Microsoft access database, which was built for this purpose and analysis was done using SPSS version 18 with appropriate statistical tests.

We first describe sociodemographics, continuous variables and crosstabs looking for difference between old and new patients and also between Ctr(-) and $\operatorname{Ctrl}(+)$. Finally we perform a logistic regression to look for blood pressure control predictors.

\section{Results}

Our sample was representative making more than one third of the patients seen in the study period. It involved 286 patients with 180 old Patients and 106 new Patients with $68.2 \%$ being female, $46.2 \%$ from age group 60 and more. Patients 
were unschooled in $81.5 \%$, from low income group in 58.4\% (Table 1). There was no statistical difference in sociodemographics between older and newly diagnosed patients.

Tobacco smoking, Diabetes, dyslipidemia and high uric acid (HUA) were other cardiovascular risk factors found in respectively 4.8, 10.4, 12.5 and 17.8\% of all cases (Table 1) without statistical difference between older and newly diagnosed patients.

Among continuous variables, only systolic blood pressure (SBP) was higher for new Patients $(p=0.014)$. Age, creatinine clearance, heart rate, weight, height, WC, BMI, diastolic blood pressure (DBP) haven't show any statistically significant difference (Table 2).

At 3 months globally 40.90\% (31.1 for old Patients and 09.8\% for new Patients ) of the sample were controlled (Figure 1).

For old Patients hypertension control rate at inclusion was $12.78 \%$ and reached $49.44 \%$ at 3 months.

During the study period therapeutic regimen remained unchanged in $73.1 \%$ (44.4 for old Patients and 28.7 for new Patients (Table 3). There were 2 old Patients by whom temporarily discontinuation or breaking was noted.

Table 1. Sociodemographics and risk factors or the sample of 286 hypertensive patients.

\begin{tabular}{|c|c|c|c|c|c|}
\hline Variables & & Old Patients & New Patients & Total & $p$ \\
\hline \multirow{2}{*}{ Sex } & Male & 17.5 & 14.3 & 91 & 0.056 \\
\hline & Female & 45.5 & 22.7 & 195 & \\
\hline \multirow{5}{*}{ Age group } & $<30$ & 01.7 & 01.4 & 9 & 0.701 \\
\hline & $30-44$ & 10.5 & 05.2 & 45 & \\
\hline & $45-59$ & 23.1 & 11.9 & 100 & \\
\hline & $\geq 60$ & 27.6 & 18.5 & 132 & \\
\hline & 0 & 50.3 & 31.1 & 233 & 0.692 \\
\hline \multirow[t]{3}{*}{ School attending (years) } & $1-9$ & 1.7 & 0.7 & 7 & \\
\hline & 10 and more & 10.8 & 05.2 & 46 & \\
\hline & Low & 37.1 & 21.3 & 167 & 0.645 \\
\hline \multirow[t]{2}{*}{ Income* } & Middle & 21.3 & 11.9 & 95 & \\
\hline & NA & 04.5 & 03.8 & 24 & \\
\hline \multirow[t]{2}{*}{ Tobacco smoking } & No & 59.8 & 35.3 & 272 & 0.915 \\
\hline & Yes & 3.1 & 1.7 & 14 & \\
\hline \multirow[t]{2}{*}{ Diabetes } & No & 5.63 & 33.2 & 256 & 0.962 \\
\hline & Yes & 06.6 & 03.8 & 30 & \\
\hline \multirow[t]{2}{*}{ Dyslipidemia } & No & 54.9 & 32.5 & 250 & 0.899 \\
\hline & Yes & 08.0 & 04.5 & 36 & \\
\hline \multirow[t]{2}{*}{ Hyperuricemia } & No & 51.4 & 30.8 & 235 & 0.773 \\
\hline & Yes & 11.5 & 06.3 & 51 & \\
\hline
\end{tabular}

*Income: based on monthly salary. Low for $<90$ USD, Middle for $\geq 90$ and <540 USD, NA: No Answer. 
Table 2. Distribution of descriptives in the sample of 289 hypertensive patients.

\begin{tabular}{ccccccccccc}
\hline \multirow{2}{*}{ Variables } & \multicolumn{3}{c}{ Old Patients } & \multicolumn{3}{c}{ New Patients } & \multicolumn{3}{c}{ Total } & $p$ \\
\cline { 2 - 11 } & Mean & N & SD & Mean & N & SD & Mean & N & SD & \\
\hline Age (years) & 55.04 & 180 & 12.761 & 55.53 & 106 & 12.709 & 55.22 & 286 & 12.722 & 0.754 \\
"CrCl at inclusion & 85.61 & 145 & 29.176 & 84.85 & 79 & 30.266 & 85.34 & 224 & 29.499 & 0.855 \\
HR $^{*}$ & 82.39 & 178 & 15.385 & 85.82 & 106 & 15.285 & 83.67 & 284 & 15.411 & 0.069 \\
Weight (Kg) & 74.22 & 180 & 16.401 & 73.84 & 106 & 15.553 & 74.08 & 286 & 16.065 & 0.848 \\
Height (cm) & 164.69 & 180 & 7.353 & 165.53 & 106 & 7.148 & 165.00 & 286 & 7.276 & 0.347 \\
WC** & 93.69 & 180 & 14.897 & 91.52 & 106 & 12.695 & 92.89 & 286 & 14.137 & 0.209 \\
BMI*** $^{*}$ & 28.45 & 180 & 6.148 & 27.83 & 106 & 5.778 & 28.22 & 286 & 6.011 & 0.394 \\
SBP $^{+}$ & 156.93 & 178 & 26.459 & 165.63 & 104 & 31.747 & 160.14 & 282 & 28.777 & 0.014 \\
DBP $^{++}$ & 95.08 & 178 & 14.076 & 96.57 & 104 & 19.108 & 95.63 & 282 & 16.098 & 0.456 \\
MAP $^{++}$ & 115.70 & 178 & 16.609 & 119.59 & 104 & 21.170 & 117.13 & 282 & 18.481 & 0.088 \\
\hline
\end{tabular}

${ }^{*}$ Creatinine clearance; ${ }^{*}$ heart rate; ${ }^{* *}$ Waist circumference; ${ }^{* *}$ Body mass index; ${ }^{+}$Systolic blood pressure; ${ }^{++}$Diastolic blood pressure; ${ }^{+++}$Mean arterial pressure.

Table 3. Distribution of therapeutical regimen changes.

\begin{tabular}{cccc}
\hline Molecules Changed & Old patients (\%) & New patients (\%) & Total \\
\hline No & 44.4 & 28.7 & 209 \\
1 added & 9.4 & 5.9 & 044 \\
2 added & 0.3 & 0.0 & 001 \\
1 added, 1 replaced & 01.4 & 0.0 & 004 \\
1 retired & 0.3 & 0.3 & 002 \\
1 retired, 1 replaced & 0.3 & 0.3 & 002 \\
1 replaced & 5.9 & 1.4 & 021 \\
2 replaced & 0.7 & 0.3 & 003 \\
Total & 62.9 & 37.1 & 286 \\
\hline
\end{tabular}

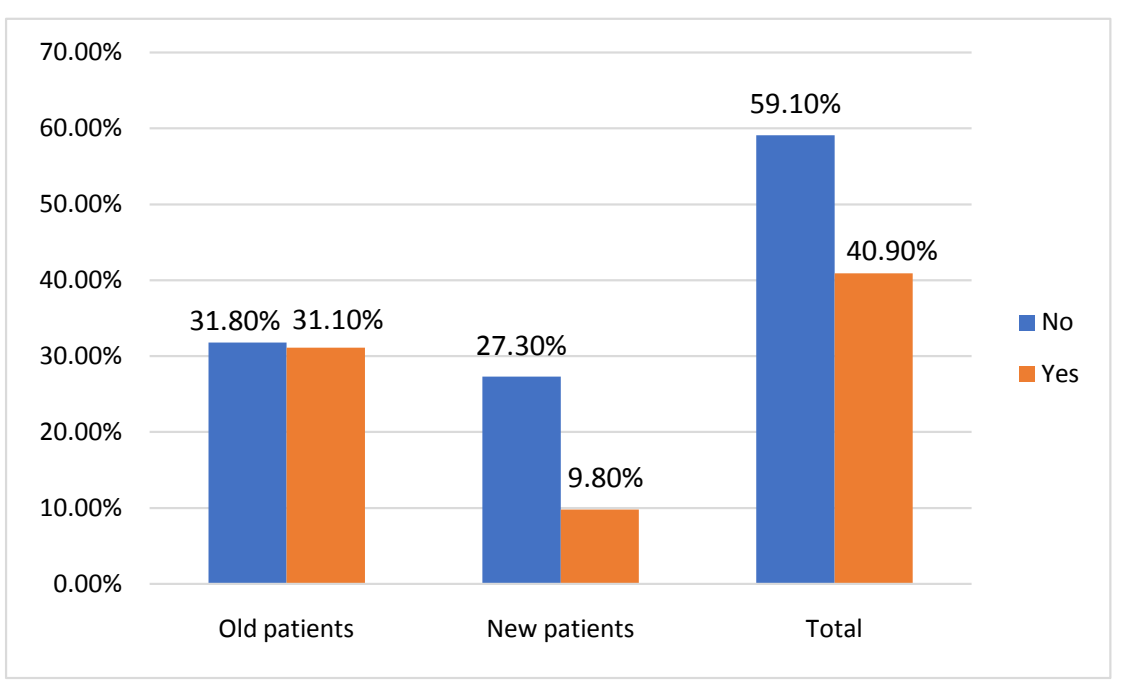

Figure 1. Blood pressure control rate at 3 months. 
Calcium channel blocker (CCB), diuretics (DIU) and ACE-inhibitors (ACE-I) were the most prescribed drugs without statistical difference between patients with and without blood pressure under control (Figure 2).

Old patients had higher prescriptions rate for all antihypertensive classes except for angiotensin receptor type 2 (ARA2) with a statistical significant difference for beta-blocker (BB). There was always more CCB, DIU and ACE-I as most prescribed antihypertensive molecules (Figure 3).

By looking for factors related to blood pressure control, we found only HTN duration as significant predictor. Odd-ratio for HBP duration with old patients as reference was 0.365 [0.213 - 0.624] 95\% CI and $p$-value $<0.001$ meaning that new patients were less likely to have their blood pressure controlled (Table 4). Old patients had mostly tritherapy whereas new one had monotherapy prescribed (Figure 4).

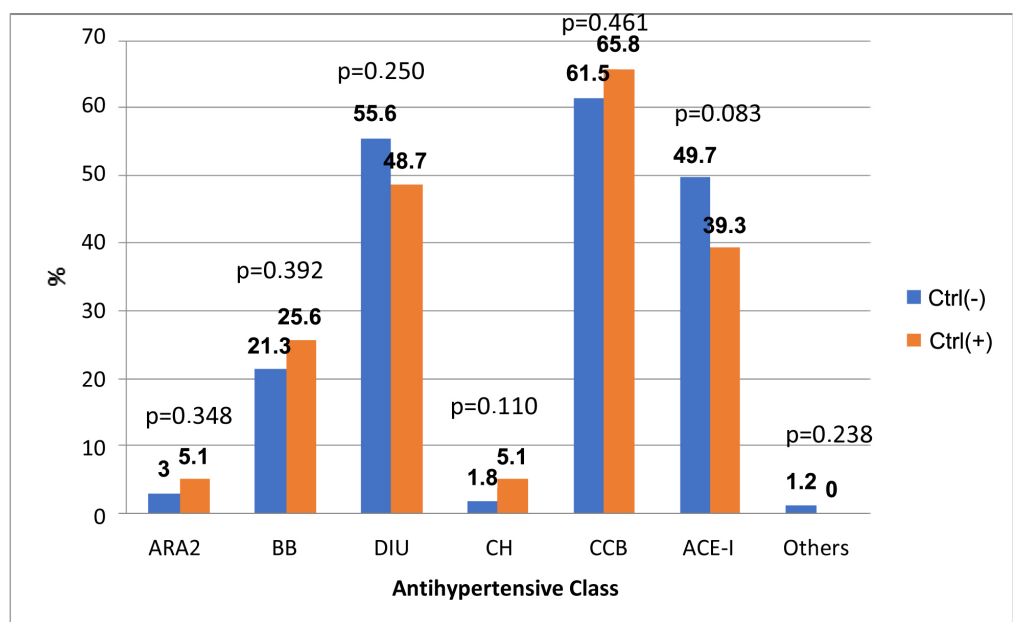

Figure 2. Antihypertensive molecules and control status. ARA2: angiotensin receptor typ 2 antagonist, BB: beta-blocker, DIU: diuretic, $\mathrm{CH}$ : central antihypertensivum, CCB: calcium channel blocker, ACE-I: angiotensin converting enzyme inhibitor.

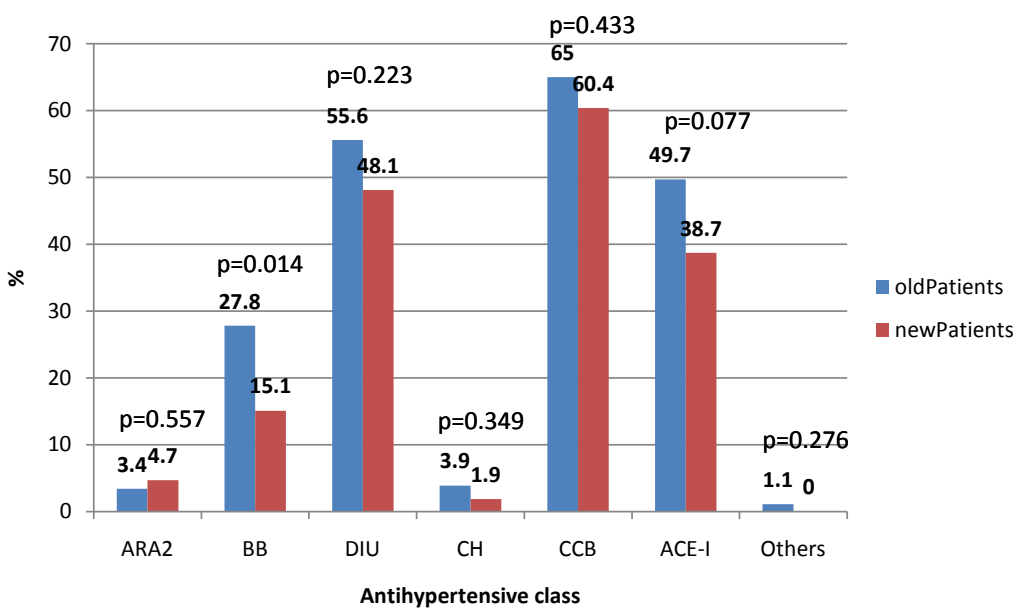

Figure 3. Antihypertensive molecules related to duration category. ARA2: angiotensin receptor typ 2 antagonist, $\mathrm{BB}$ : beta-blocker, DIU: diuretic, $\mathrm{CH}$ : central antihypertensivum, CCB: calcium channel blocker, ACE-I: angiotensin converting enzyme inhibitor. 
Table 4. Factors associated with blood pressure control.

\begin{tabular}{|c|c|c|c|}
\hline \multirow{2}{*}{ Factors } & \multirow{2}{*}{ OR } & \multicolumn{2}{|c|}{$95 \%$ C.I. for OR } \\
\hline & & Lower & Lower \\
\hline Sex Male as reference $\chi^{2}(1)=0.154(1), p=0.695$ & 1.161 & 0.552 & 2.440 \\
\hline \multicolumn{4}{|l|}{ Age in years $<30$ as reference $\chi^{2}(3)=1.446, p=0.695$} \\
\hline $30-44$ & 0.727 & 0.154 & 3.436 \\
\hline $45-59$ & 0.955 & 0.216 & 4.226 \\
\hline 60 and more & 0.691 & 0.157 & 3.039 \\
\hline \multicolumn{4}{|l|}{ School attending in years 0 as reference $\chi^{2}(2)=1.230, p=0.541$} \\
\hline $1-9$ & 2.539 & 0.488 & 13.222 \\
\hline $10+$ & 1.111 & 0.500 & 2.468 \\
\hline Income Level Low as reference $\chi^{2}(1)=1.895, p=0.169$ & 0.617 & 0.311 & 1.227 \\
\hline Tobacco smoking No as reference $\chi^{2}(1)=0.026, p=0.872$ & 0.902 & 0.258 & 3.152 \\
\hline Diabetes No as reference $\chi^{2}(1)=0.446, p=0.504$ & 1.326 & 0.579 & 3.035 \\
\hline WC* Normal as reference $\chi^{2}(1)=0.036, p=0.849$ & 0.934 & 0.460 & 1.893 \\
\hline \multicolumn{4}{|l|}{$\mathrm{BM}^{* *} \mathbf{I}$ Normal as reference $\chi^{2}(2)=1.899, p=0.387$} \\
\hline Overweight & 1.034 & 0.520 & 2.057 \\
\hline Obesity & 0.658 & 0.278 & 1.558 \\
\hline HTN $^{* * *}$ duration Old patients as reference $\chi^{2}(1)=13.578, p<0.001$ & 0.365 & 0.213 & 0.624 \\
\hline
\end{tabular}

* waist circumference; ${ }^{* *}$ body mass index; ${ }^{* * *}$ hypertension.

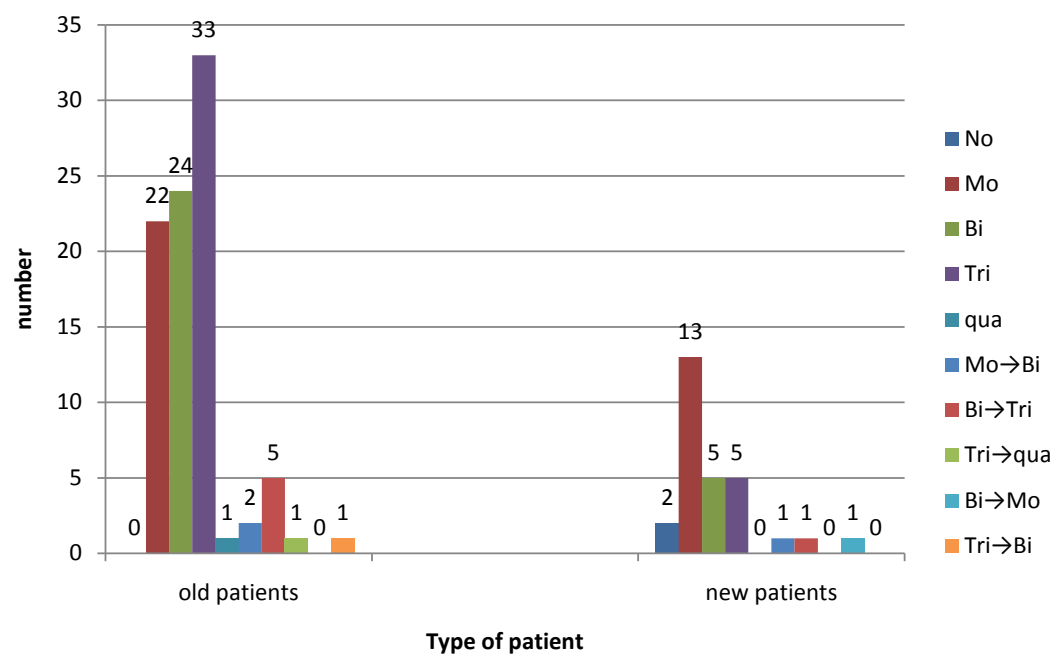

Figure 4. Repartition of number of prescribed molecules in relation to patient type. No: no medication; Mo: monotherapy; Bi: bitherapy; Tri: tritherapy; Qua: quadritherapy.

\section{Discussion}

Our study, the first in its kind presents some interesting findings about HTN and its control rate in hospital area:

1) The sample with more patients in low income category and mostly unschooled reflects the population structure in our country.

2) Typical cardiovascular risk factors such as tobacco, Diabetes, dyslipidemia 
were found as in most studies [13] [14] [15].

3) As shown in Figure 1 control rate at 3 months remains low with $40.90 \%$ old patients having a higher control rate of 31.1. We didn't find previous data on hypertension control rate in Mali. HBP control rate is generally poor in most countries with $14.9 \%$ in some regions of China [16] but varied considerably from $27 \%$ in England to $66 \%$ in Canada [4]. Trends showed increasing but this remains low for example 2 - 21 for all, 12 - 37 for aware and 9\% to 49\% for treated hypertensive patients [8].

We saw an increase in control rate for old patients in the short term. This could be due to close follow-up and provided information in the study time. He et al. [12] pointed out the fact that a regular source of health care and modification of lifestyle are important factors in the control of hypertension in the community. That could explain why our old patients had a higher control rate

1) Some factors were found to be associated with a better control rate of HTN such as repeated blood pressure measure, being aware of HTN diagnosis and taking lifestyle modification [11]. In our study lifestyle modifications could not be assessed as they need time longer than just 3 months.

2) Our patients got with decreasing proportion CCB, DIU and ACE-I in the same order as for old and new patients well for patients with and without controlled HBP according to recommendations. Control rate remained low despite as for most countries [17] even we know from the COMFORT study that adherence to antihypertensive drug regimen is related to blood pressure control [18]. More over combination antihypertensive therapy is often needed to reach BP goal [19].

We could not test strategy as described by Kamel et al. [20] due to cost issues, most of our patients being without medical insurance. It appeared also clear that medication is necessary for blood pressure control as shown in Figure 4. Only 2 patients had their hypertension controlled without medication.

\section{Limits}

Our study extended only about 3 months and will not give information about control rate in long term and also about the sustainability of controlled blood pressure. It will be also interesting to try to repeat the same study in a year looking for trends in the hypertension control rate or further looking for associated factors.

\section{Conclusion}

Our study gave control rate in short period; sustainability should be assessed in a longer time. Hypertension duration was the only factor which was associated with its control. Fast all patients need medication.

\section{References}

[1] Wolrd Health Organization. A Global Brief on Hypertension. 
http://apps.who.int/iris/bitstream/handle/10665/79059/WHO_DCO_WHD_2013.2 _eng.pdf

[2] Kearney, P.M., et al. (2005) Global Burden of Hypertension: Analysis of Worldwide Data. Lancet, 365, 217-223.

[3] Roth, G.A., Huffman, M.D., Moran, A.E., Feigin, V., Mensah, G.A., Naghavi, M. and Murray, C.J.L. (2015) Global and Regional Patterns in Cardiovascular Mortality from 1990 to 2013. Circulation, 132, 1667-1678.

[4] Joffres, M., Falaschetti, E., Gillespie, C., et al. (2013) Hypertension Prevalence, Awareness, Treatment and Control in National Surveys from England, the USA and Canada, and Correlation with Stroke and Ischemic Heart Disease Mortality: A cross-Sectional Study. BMJ, 3, e003423. https://doi.org/10.1136/bmjopen-2013-003423

[5] Ma, J. and Stafford, R.S. (2008) Screening, Treatment, and Control of Hypertension in US Private Physician Offices, 2003-2004. Hypertension, 51, 1275-1281. https://doi.org/10.1161/HYPERTENSIONAHA.107.107086

[6] Houlihan, S.J., Simpson, S.H., Cave, A.J., et al. (2009) Hypertension Treatment and Control Rates: Chart Review in an Academic Family Medicine Clinic. Canadian Family Physician, 55, 735-741.

[7] McAlister, F.A., Wilkins, K., Joffres, M., et al. (2011) Changes in the Rates of Awareness, Treatment and Control of Hypertension in Canada over the Past Two Decades. CMAJ: Canadian Medical Association Journal, 183, 1007-1013. https://doi.org/10.1503/cmaj.101767

[8] Gupta, R., et al. (2017) 25 Years Trends in Hypertension Prevalence, Awareness, Treatment, and Control Rate in an Indian Urban Population: Jaipur Heart Watch. Indian Heart Journal.

[9] Roy, A., Praveen, P.A., Amarch, R., et al. (2017) Changes in Hypertension Prevalence, Awareness, Treatment and Control Rates over 20 Years in National Capital Region of India: Results from a Repeat Cross-Sectional Study. BMJ, 7, e015639. https://doi.org/10.1136/bmjopen-2016-015639

[10] Ikeda, N., Sapienza, D., Guerrero, R., et al. (2014) Control of Hypertension with Medication: A Comparative Analysis of National Surveys in 20 Countries. Bulletin of the World Health Organization, 92, 10-19C. http://www.who.int/bulletin/volumes/92/1/13-121954 https://doi.org/10.2471/BLT.13.121954

[11] Muntner, P., Gu, D.F., Wu, X.Q., Duan, X.F., Gan, W.Q., Whelton, P.K. and He, J. for the InterASIA Collaborative Group (2004) Factors Associated with Hypertension Awareness, Treatment, and Control in a Representative Sample of the Chinese Population. Hypertension, 43, 578-585.

[12] He, J., Muntner, P., Chen, J., Roccella, E.J., Streiffer, R.H. and Whelton, P.K. (2002) Factors Associated with Hypertension Control in the General Population of the United States. Archives of Internal Medicine, 162, 1051-1058.

https://doi.org/10.1001/archinte.162.9.1051

[13] Esteghamati, A., Abbasi, M., Alikhani, S., Gouya, M.M., Delavari, A., Shishehbor, M.H., Forouzanfar, M., Hodjatzadeh, A. and Ramezani, R.D. (2008) Prevalence, Awareness, Treatment, and Risk Factors Associated with Hypertension in the Iranian Population: The National Survey of Risk Factors for Noncommunicable Diseases of Iran. American Journal of Hypertension, 21, 620-626. https://doi.org/10.1038/ajh.2008.154

[14] Amelor, S., Kweku, M., Agboli, E., et al. (2016) Risk Factors Associated with 
Hypertension among Adults in the Hohoe Municipality, Ghana. BJMMR, 18, 1-12. https://doi.org/10.9734/BJMMR/2016/29463

[15] Gebreselassie, K.Z. and Padyab, M. (2015) Epidemiology of Hypertension Stages in Two Countries in Sub-Sahara Africa: Factors Associated with Hypertension Stages. International Journal of Hypertension, 2015, Article ID: 959256.

[16] Yin, M. et al. (2016) Geographic Distributions in Hypertension Diagnosis, Measurement, Prevalence, Awareness, Treatment and Control Rates among Middle-Aged and Older Adults in China. Scientific Reports, 6, 37020. https://doi.org/10.1038/srep37020

[17] Nayu, I., et al. (2014) Control of Hypertension with Medication: A Comparative Analysis of National Surveys in 20 Countries. Bulletin of the World Health Organization, 92, 10-19C. https://doi.org/10.2471/BLT.13.121954

[18] Matsumura, K., Arima, H., Tominaga, M., Ohtsubo, T., Sasaguri, T., Fujii, K., Fukuhara, M., Uezono, K., Morinaga, Y., Ohta, Y., Otonari, T., Kawasaki, J., Kato, I., Tsuchihashi, T., The Comfort Investigators (2013) Impact of Antihypertensive Medication Adherence on Blood Pressure Control in Hypertension: The COMFORT Study. QJM: An International Journal of Medicine, 106, 909-914.

[19] Bakris, G., Sarafidis, P., Agarwal, R. and Ruilope, L. (2014) Review of Blood Pressure Control Rates and Outcomes. Journal of the American Society of Hypertension, 8, 127-141. https://doi.org/10.1016/j.jash.2013.07.009

[20] Gharaibeh, K.A., Turner, S.T., Hamadah, A.M., Chapman, A.B., Cooper-Dehoff, R.M., Johnson, J.A., Gums, J.G., Bailey, K.R. and Schwartz, G.L. (2016) Comparison of Blood Pressure Control Rates among Recommended Drug Selection Strategies for Initial Therapy of Hypertension. American Journal of Hypertension, 29, 1186-1194. 